\title{
Assessment of roadway bridges damaged by human errors using risk indicators and robustness index
}

\author{
Neryvaldo Galvão \\ $1^{\text {st }}$ year PhD student, University of Minho, Guimarães, Portugal \\ José Campos e Matos, Daniel Oliveira \\ Professor, University of Minho, Guimarães, Portugal
}

Carlos Santos

Msc student, University of Minho, Guimarães, Portugal

Contacting author: neryvaldo.galvao17@live.com

\begin{abstract}
To the bridges failures that have been arising over the years, experts have pointed out as the main cause of failure, human errors, in the design, construction and operation phases. One of the main goals of this paper is the identification of the foremost causes of failure due to human errors in design and construction procedures. Therefore, a bridge failure database that includes several failure cases and a human errors survey will be used to support this line of work. After the identification of some explicit human errors that is believed to be the source of several reinforced concrete bridges failures, a selective analysis using risk indicators, namely, the probability of occurrence and consequence, is performed to choose those that might represent a higher risk for the structural safety. The outcome of five selected human errors in a specific case study is quantified using a robustness index, computed according to the variation of the structure reliability index due to the damages caused by human errors, allowing to demonstrate their impact in the structural safety. The modelling process and the finite element analysis of the structure is performed using TNO DIANA software, allowing the calculation of the reliability index of the structure damaged by different human errors. Within the COST action TU-1406, the main goal of this work is a contribution for the establishment of a roadways bridge quality control plan with higher efficiency in the reduction of bridge failures, their mortality rates and economic loss.
\end{abstract}

Keywords: bridge failure, reinforced concrete bridges, human error, risk analysis, non-linear structural analysis, probabilistic assessment and robustness analysis.

\section{Introduction}

The transportation system, as one of the key elements for economic development and the fulfilment of human happiness, has always been a valuable asset for societies. Nevertheless, the transportation system depends very often on connections provided by roadway, railway and 
footway bridges. Thus, these infrastructures have a crucial role to play in the transportation network, being responsible for tremendous consequences when wrongly managed, as revealed in the literature [1] and the daily news.

To improve the safety of bridges is first required, the screening of the main sources of the uncertainties that have been leading them to fail. Relying on a bridge failure database, that to the author's knowledge, is one of the most completed available database, developed by [2] with more than 450 worldwide bridge failure incidents since 1966 to 2017, covering the leading causes of failure (Figure 1), is inevitable the conclusion that the human errors are the primary source of uncertainties leading to bridge failure and collapse.

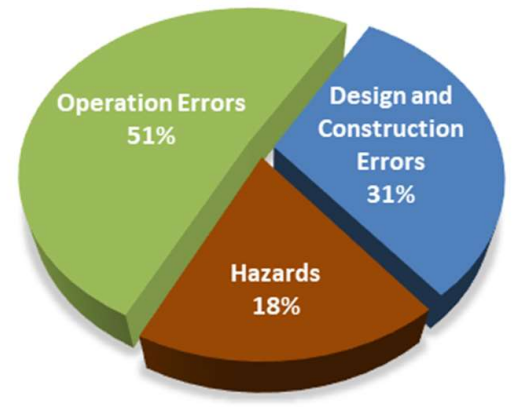

Figure 1. Leading causes of failure for reinforced concrete bridges [2]

\section{Risk analysis of design and construction errors}

The design and construction errors are a vast subject and when it comes to being explicitly defined, the engineers might find themselves very confused in the definition of their boundaries and their identification in the complex conception process of a bridge. In this the paper, the human error is defined as being any design, construction and operation errors that don't exceed the currently available engineering knowledge, and which took place due to poor working conditions, lack of training, supervision and check-up procedures. These errors or uncertainties are not covered by the safety factors of the current standards. A similar definition of human error is given by [3] and [4]. The human errors usually assume different shapes and magnitudes thus they represent different risks and they may also represent different risks for different structures. Therefore, it is crucial the identification of those that may well represent a greater risk, for better quality control and more effective mitigation approach. In order to identify more than a few design and construction errors with some impact in the structural serviceability and safety, a brainstorming meeting with several experts of the construction industry was set. A total of 20 design and 29 construction errors were identified towards a prestressed reinforced concrete bridge. Afterwards, these errors were compilated and disseminated on a very well-structured survey, in order to assess, qualitatively, each one of them according to their probability of occurrence and the consequence. The results of the survey were treated according to the analytical hierarchical process bestowed by [5], allowing to rank the errors according to the overall risk they represent for the structure. The wide-ranging identification of all the errors and the complete analysis carried out can be found in [6].

\section{Case study - Numerical analysis}

The longitudinal profile of the case study is a threespan bridge of $18 m+27.8 m+18 m$, consequently with a total length of $63.8 \mathrm{~m}$. The bridge deck is rigidly connected to each pier by means of a transversal girder with $3 \mathrm{~m}$ height. The connection of the deck to the abutment is carried out by means of a simply supported transversal girder with a height of $1.9 \mathrm{~m}$. The piers are supported by a deep spread foot foundation, built more than $3.0 \mathrm{~m}$ below the road platform. The representative transversal cross-section of the deck comprises a set of three pre-cast I-beams with a total height of $1.5 \mathrm{~m}$. The beams were pre-cast with $\mathrm{C} 45 / 55$ concrete and prestressed by means of pretensioned strands in its upper and lower flange, while they are under simple support static condition. Therefore, the continuity of the deck over the piers is only ensured by the passive reinforcements found in the cast in-situ slab and in the pre-cast beams, hence, no hyperstatic stress is developed on the deck due to the prestress forces. For the elements cast in situ a C30/37 concrete, was used. The concrete slab has $0,25 \mathrm{~m}$ of thickness and $8,9 \mathrm{~m}$ of width, giving rise to a cross-section whose maximum height is $1,75 \mathrm{~m}$ (Figure 2). 


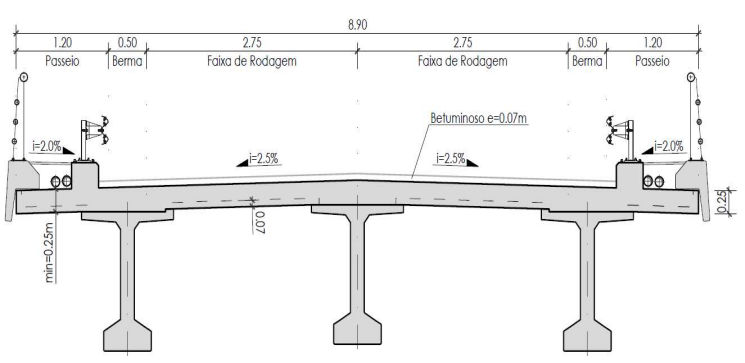

Figure 2. Transversal deck cross-section

The numerical model of the case study is shaped using a beam element with three degrees of freedom per nodes. This choice was made, taking into account the reduction of the computational cost of the numerical non-linear analysis, and consequently the computational cost of the probabilistic analysis to be performed. To model the deck cross-sections, an equivalent crosssection to the original one was determined due to some limitations of the finite element software, when it comes to $2 \mathrm{D}$ numerical models [7]. The constitutive models used to describe the tensile and compressive behaviour of concrete and the reinforcement comes respectively from the Eurocodes [8] and [9]. The load bearing capacity of the structure is verified according to load model 1 (LM1) of [10]. The load distribution given by the LM1 when properly converted into its equivalent longitudinal distribution, will match a uniformly distributed load of $47,75 \mathrm{kN} / \mathrm{m}$ and two concentrated loads of $500 \mathrm{kN}$ each, spaced apart by $1.2 \mathrm{~m}$. The positioning of the live load is performed according to the location of the critical section, which, in a first analysis was shown to be the midspan section of the central span. According to the static system, the bending moment influence line of the critical section is draw leading to the positioning of $\mathrm{LM} 1$, in order to amplify its bending moment effect (Figure 3). With the numerical model set according to the real case study design conditions, the load-bearing capacity of the virgin structure, based on the mean value of its random variables, is determined through an incremental load procedure that traces the non-linear behaviour of the structure until its failure.

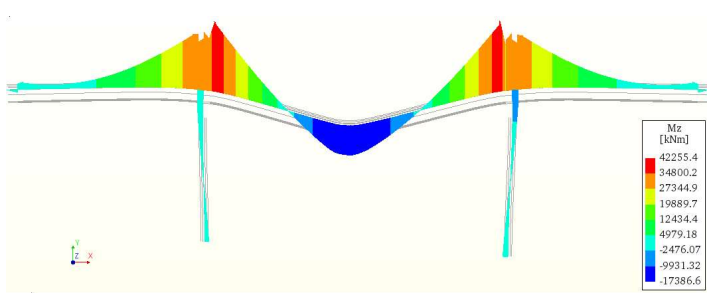

Figure 3. Bending moment distribution for maximum load factor

The failure of the system occurs due to the concrete crushing in the deck critical section after the yielding of the reinforcement and a bending moment redistribution throughout the structural system, for a load factor of 4.5. (Figure 4).

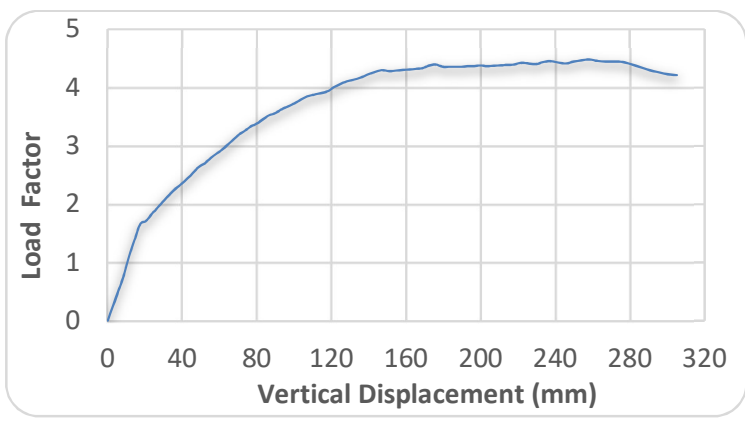

Figure 4. Vertical displacement of the critical cross section with load increase

\section{Probabilistic analysis}

The probabilistic analysis takes into account several uncertainties related to the structural real conditions, such as geometrical uncertainties, mechanical uncertainties, material uncertainties, numerical model uncertainties and action model uncertainties. All these uncertainties are taken in to account through a group of random variables characterized by several well established probabilistic distribution that leads to the computation of the structural system failure probability and reliability [11]. Aiming the achievement of the case study reliability index, all random variables that are part of the numerical problem was identified and statistically characterized according to the literature (Table 1). To every random variable was assigned an identification number (ID) used to introduce the results of a sensitivity analysis performed according to (Matos et al. 2016), which aims the reduction of the random variables involved in the 
probabilistic analysis. According to this importance factor $\left(b_{k}\right)$ given by the chosen approach, the random variables with the highest influence on the load-bearing capacity of the structure are identified. A threshold value of $10 \%$, for the importance factor, is considered to identify the random variables with high influence on the structural performance of the case study. Thus, they are, the compressive strength of the concrete, the thickness of the deck slab, the area of the longitudinal reinforcement and the ultimate yielding stress of the ordinary and prestressing reinforcement. However, the yielding stress of the ordinary reinforcement is the most influential of all random variables (Figure 5). In order to determine the reliability index of the case study, the Latin hypercube method was implemented according to [12], through a developed Matlab script to determine the maximum load factor of the 100 samples, generated by the method, using TNO DIANA software with its non-linear analysis tools. With the output results of each Latin hypercube sample, the probabilistic distribution of the structure resistance is obtained according to the uncertainties that surround the numerical problem (Figure 6). Since the resistance of the structure is given by a multiplication factor of the LM 1 , the probabilistic distribution of the load model can be measured as a unit factor of the resistance curve.

Table 1. Random variables and their statistical properties used in the probabilistic analysis

\begin{tabular}{|c|c|c|c|c|c|c|c|}
\hline ID & Description & Random Variables & Notation & $\begin{array}{c}\text { Nominal } \\
\text { Values }\end{array}$ & Bias & cov & Reference \\
\hline 1 & \multirow{4}{*}{ C30/37 } & $\begin{array}{l}\text { Compressive } \\
\text { strength }\end{array}$ & $\mathrm{fcm}$ & $30 \mathrm{MPa}$ & 1.27 & $12 \%$ & Wisniewski (2007) \\
\hline 2 & & Tensile strength & fctm & $2.0 \mathrm{MPa}$ & 1.45 & $20 \%$ & $\begin{array}{l}\text { Eurocode (2002), } \\
\text { Wisniewski (2007) }\end{array}$ \\
\hline 3 & & $\begin{array}{c}\text { Modulus of } \\
\text { elasticity }\end{array}$ & Ecm & $33 \mathrm{GPa}$ & 1.00 & $8 \%$ & Wisniewski (2007) \\
\hline 4 & & $\begin{array}{l}\text { Deck slab } \\
\text { thickness }\end{array}$ & e & $25 \mathrm{~cm}$ & 1,00 & $3,5 \%$ & Wisniewski (2007) \\
\hline 5 & \multirow{3}{*}{$\mathrm{C} 45 / 55$} & $\begin{array}{c}\text { Compressive } \\
\text { strength }\end{array}$ & $\mathrm{fcm}$ & $45 \mathrm{MPa}$ & 1,18 & $9 \%$ & Wisniewski (2007) \\
\hline 6 & & Tensile strength & fctm & $2.62 \mathrm{MPa}$ & 1.45 & $20 \%$ & $\begin{array}{l}\text { Eurocode (2002), } \\
\text { Wisniewski (2007) }\end{array}$ \\
\hline 7 & & $\begin{array}{c}\text { Modulus of } \\
\text { elasticity }\end{array}$ & Ecm & $36 \mathrm{GPa}$ & 1.00 & $8 \%$ & Wisniewski (2007) \\
\hline 8 & \multirow{2}{*}{ S500 } & $\begin{array}{c}\text { Yielding and } \\
\text { ultimate strength }\end{array}$ & fsy e $f p$ & $560 \mathrm{MPa}$ & 1.12 & $5.4 \%$ & JCSS (2001) \\
\hline 9 & & $\begin{array}{c}\text { Reinforcement } \\
\text { cross section area }\end{array}$ & $A$ & -- & -- & $2 \%$ & JCSS (2001) \\
\hline 10 & \multirow[t]{2}{*}{ S1670/1860 } & $\begin{array}{c}\text { Yielding and } \\
\text { ultimate strength }\end{array}$ & fsy e $f p$ & $1258 \mathrm{MPa}$ & 1.04 & $2.5 \%$ & $\begin{array}{c}\text { JCSS, (2005), } \\
\text { Wisniewski (2007) }\end{array}$ \\
\hline 11 & & Pre-stress tension & $\sigma p$ & $1087 \mathrm{MPa}$ & 1.00 & $1.5 \%$ & Wisniewski (2007) \\
\hline 12 & $\begin{array}{l}\text { C30/37 e } \\
\text { C45/55 }\end{array}$ & $\begin{array}{c}\text { Concrete self- } \\
\text { weight }\end{array}$ & $\gamma c$ & $25 \mathrm{kN} / \mathrm{m} 3$ & 1.03 & $8 \%$ & $\begin{array}{c}\text { JCSS (2001) } \\
\text { Wisniewski (2007) }\end{array}$ \\
\hline
\end{tabular}

The coefficient of variation of the load model 1 was considered to be $15 \%$ according to [13] and [16]. Nevertheless, the ideal solution would be to obtain the probabilistic distribution of the load through a histogram sustained by monitoring data of the crossing vehicles over the bridge. The numerical model uncertainties of the structure related to its resistance moment capacity were considered according to JCSS, using a lognormal distribution with a mean value equal to 1.2 and a coefficient of variation of 0.15 . The model uncertainties are usually the result of negligence of for example 3Deffects, inhomogeneities, interactions, boundary effects, simplification of connection behaviour, 
imperfections and so on. In other words, they take in to account the random effects that are neglected in the models and simplifications of the mathematical relations. The recommended values given by JCSS are more or less for standard structural Finite Element Model [17].

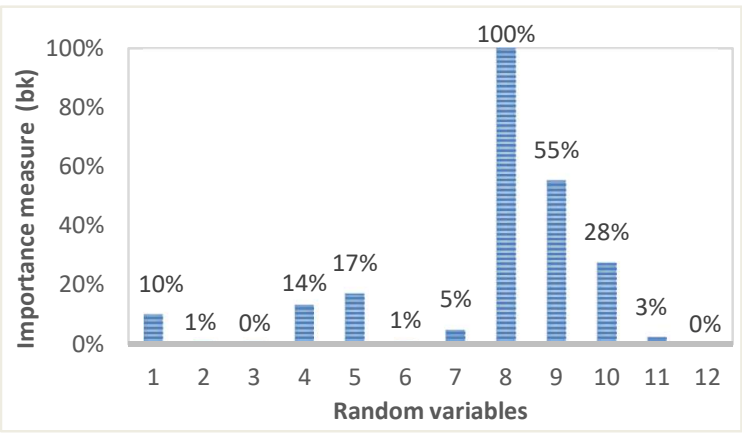

Figure 5. Random variables sensitivity analysis

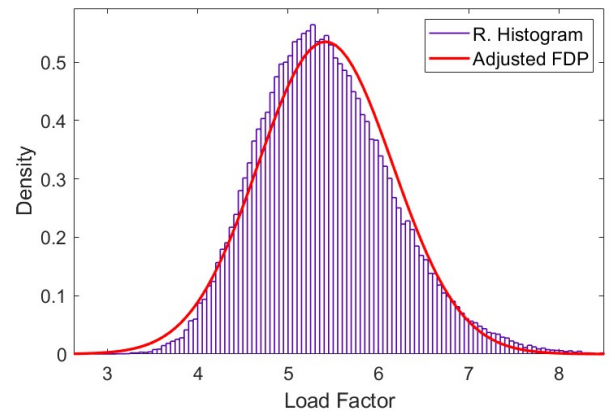

Figure 6. Probabilistic distribution of the case study load bearing capacity

Through the normal probabilistic distribution function that characterize the resistance and the load uncertainties, the formulation presented in [18] is used to compute the structural reliability index $(\beta)$, where $\mu_{R}$ and $\mu_{s}$ respectively represent the mean value of the resistance and the load, and $\sigma_{R}$ e $\sigma_{S}$ respectively represent the standard deviation of the resistance and the load. Therefore:

$$
\beta=\frac{\mu_{R}-\mu_{S}}{\sqrt{\sigma_{R}^{2}+\sigma_{S}^{2}}}=\frac{5.41-1}{\sqrt{0.746^{2}+0.15^{2}}}=5.80
$$

By comparing the obtained reliability index with the target reliability index of 4.4 given in ISO 2394:2015, it can then be stated that the case study is in good safety condition. Considering that the entire modelling procedure is based on the design report, without taking into account any kind of damage or degradation that the structure might be exposed, the obtained reliability index value is reasonable. It should also be stated here that the analysis carried out is relative to the whole system, thus considering the bending moment redistribution through the structural system. In other words, the analysis is not limited to a section resistance capacity, as usual, where the values of the reliability index are often of lower orders.

\section{Robustness assessment}

Structural robustness is defined by [19] as the ability of a structure to withstand events such as fires, explosions, impact or consequences of human error without being damaged to an extent disproportionate to the original cause. Hence, the robustness analysis takes for granted the quantification of the proportionality between the impact or consequence of certain damage and its magnitude. Within the scope of this paper, the impact of a certain damage caused by a human error is measured through the global variation of the structure reliability index. In order to perform the structure robustness analysis, a group of three design error (DE) and two construction error (CE) is considered. These errors were nominated from an extensive list of error, highlighted in chapter two, according to the following criteria: (i) the ease of modelling the damage caused by the error; (ii) the adaptability of the error to the case study; and (iii) the risk associated with each error (Table 2). The damages caused by the construction and design error are modelled deterministically according to the numerical parameters and the magnitude presented in Table 3. The magnitude or severity of the error is presented in Figure 7 by means of percentages values along with its normalized reliability index, in order to simplify the results reading. Thus, the impact of each error in the safety condition of the structure is evaluated. To model the Damage 1 the permanent load was increased throughout the structure. The Damage 2 was modelled by decreasing the upper and the lower deck slab reinforcement cross-section area. The deck slab reinforcement was chosen over the precast girders because it was conceived in a more controlled environment which represent a lower probability of error when compared to the placement of the reinforcement on site. 
Table 2. Damages used for robustness analysis of the case study

\begin{tabular}{clc}
\hline Damages & \multicolumn{1}{c}{ Errors leading to the damages } & Error type \\
\hline $\mathbf{1}$ & Error in dead load quantification & $\mathrm{DE}$ \\
\hline $\mathbf{2}$ & Error in the definition of the reinforcement cross-section area & $\mathrm{DE}$ \\
\hline $\mathbf{3}$ & $\begin{array}{l}\text { Error in the definition of the soil-structure interaction (support } \\
\text { conditions and differential settlements) }\end{array}$ & $\mathrm{DE}$ \\
\hline $\mathbf{4}$ & Error due to insufficient prestressing force & $\mathrm{CE}$ \\
\hline $\mathbf{5}$ & $\begin{array}{l}\text { Error in the manufacturing requirement of the ordered concrete, } \\
\text { giving rise to a concrete of low quality }\end{array}$ & $\mathrm{CE}$ \\
\hline
\end{tabular}

Table 3. Numerical parameters and damages magnitude used for the robustness analysis

\begin{tabular}{|c|c|c|c|c|c|}
\hline \multirow{3}{*}{$\begin{array}{l}\text { Damages } \\
\text { Damage } 1\end{array}$} & \multirow{3}{*}{$\begin{array}{c}\text { Numerical Parameters } \\
\qquad \begin{array}{c}\text { Gk1 }=98.97 \mathrm{kN} / \mathrm{m} \\
\mathrm{Gk} 2=56.16 \mathrm{kN} / \mathrm{m}\end{array}\end{array}$} & \multicolumn{4}{|c|}{ Damage Magnitude } \\
\hline & & \multirow{2}{*}{$1,15 \mathrm{Gk}$} & \multirow{2}{*}{$1,45 \mathrm{Gk}$} & \multirow{2}{*}{$1,75 \mathrm{Gk}$} & \multirow{2}{*}{$2,00 \mathrm{Gk}$} \\
\hline & & & & & \\
\hline \multirow{4}{*}{ Damage 2} & As1, sup $=54.3 \mathrm{~cm} 2$ & \multirow{4}{*}{$0,85 \mathrm{As}$} & \multirow{4}{*}{$0,55 \mathrm{As}$} & \multirow{4}{*}{$0,25 \mathrm{As}$} & \multirow{4}{*}{0,0 As } \\
\hline & As1, inf = $49.8 \mathrm{~cm} 2$ & & & & \\
\hline & As2, sup $=142.7 \mathrm{~cm} 2$ & & & & \\
\hline & As2, inf = $138.2 \mathrm{~cm} 2$ & & & & \\
\hline Damage 3 & ds & $5 \mathrm{~cm}$ & $10 \mathrm{~cm}$ & $15 \mathrm{~cm}$ & $20 \mathrm{~cm}$ \\
\hline \multirow{2}{*}{ Damage 4} & $\sigma p 1=1046.25 \mathrm{MPa}$ & \multirow{2}{*}{$0,85 \mathrm{sp}$} & \multirow{2}{*}{$0,55 \mathrm{sp}$} & \multirow{2}{*}{$0,25 \mathrm{sp}$} & \multirow{2}{*}{$0,0 \mathrm{sp}$} \\
\hline & $\sigma p 2=1087.05 \mathrm{MPa}$ & & & & \\
\hline \multirow{2}{*}{ Damage 5} & $\mathrm{fcm}, \mathrm{C} 30 / 37=38 \mathrm{MPa}$ & \multirow{2}{*}{$0,85 \mathrm{fcm}$} & \multirow{2}{*}{$0,55 \mathrm{fcm}$} & \multirow{2}{*}{$0,3 \mathrm{fcm}$} & \multirow{5}{*}{$0,2 \mathrm{fcm}$} \\
\hline & $\mathrm{fcm}, \mathrm{C} 45 / 55=53 \mathrm{MPa}$ & & & & \\
\hline \multirow{3}{*}{$\begin{array}{l}\text { Multiples } \\
\text { Damages }\end{array}$} & Gk1 e Gk2 & $1,15 \mathrm{Gk}$ & $1,45 \mathrm{Gk}$ & $1,55 \mathrm{Gk}$ & \\
\hline & ds & $5 \mathrm{~cm}$ & $10 \mathrm{~cm}$ & $11 \mathrm{~cm}$ & \\
\hline & $\begin{array}{c}\mathrm{fcm}, \mathrm{C} 45 / 55 \text { e } \mathrm{fcm} \\
\mathrm{C} 30 / 37\end{array}$ & $0,85 \mathrm{fcm}$ & $0,55 \mathrm{fcm}$ & $0,45 \mathrm{fcm}$ & \\
\hline
\end{tabular}

The soil-structure interaction (Damage 3) was modelled considering differential settlements of the piers. The following damage is modelled through the decrease of the prestress forces applied to pre-cast beams. It should be noted here that the prestressing reinforcement area was not reduced, which usually occurs when it is attacked by corrosion and can be found in the common literature.

As expected, there is a more or less marked drop of the reliability index with increasing error severity (Figure 7). Exceptionally for Damage 4, there is an increase in the reliability index. This damage outcome on the mean maximum load-bearing capacity of the structure is minimum, representing a total loss of $3.5 \%$ throughout the entire damage magnitude. However, there is a marked decrease of the standard deviation, i.e. an increase in the certainty of structure behaviour, which eventually pay off the minimum loss of load bearing capacity, thereby, increasing the reliability index. The loss of prestressing stress, despite being shown has favourable to the structure safety condition, taking into account the bending moment ultimate limit state it's not for the structure serviceability. This calls into question its decompression limit state, thus leading to larger cracks since the structure will be under higher tensile stresses. The computation of the robustness index comes from the normalization of the reliability indexes, relatively to the highest reliability index associated with each damage, in order to obtain the robustness index presented by [20]. The formulation presented by 
Cavaco, when compared to most common formulation from the literature, it gives a global evaluation of the impact of a damage since it takes into account its influence for different magnitudes through the quantification of the area below the normalized chart. Unlike Cavaco's index, the robustness index is usually computed for specific damage magnitude. The computation of the robustness index was performed considering two damage magnitude limits, one at $45 \%$ and the second at $100 \%$.

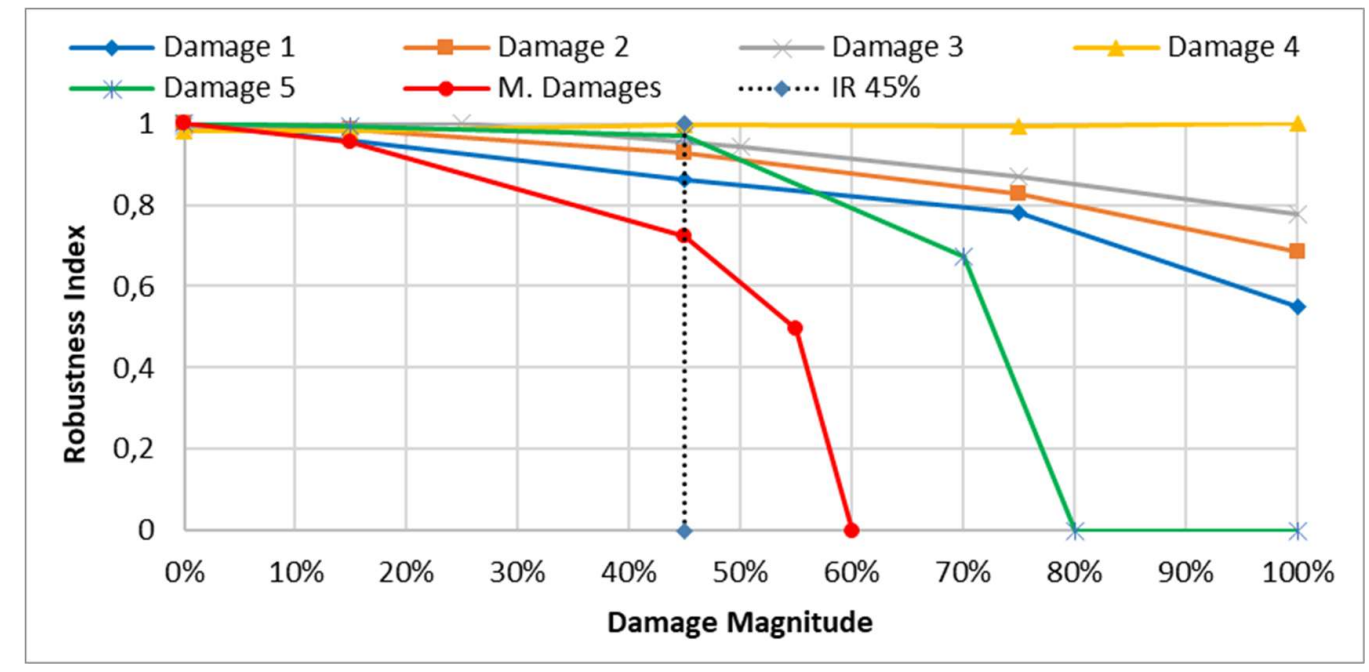

Figure 7. Robustness index reduction caused by the damage magnitude increase

In Table 4 is found the robustness index (0\%-100\%) obtained for each damage according to the previously established limits and their ranking position $\left(R_{k}\right)$. The decrease of the structure reliability index for Damage 5 exhibit two distinct behaviours, a small impact for damages magnitude below $45 \%$ and huge decrease on structure reliability for higher damages magnitude. Therefore, it might look like a neglectable error for small damages magnitude but has a tremendous impact for higher magnitude. In this sense, the importance of the proposed sensitivity analysis is demonstrated here since in this situation a punctual evaluation could lead to misleading conclusions.

\section{Conclusions}

The impact of human error should be measured in three domains: (i) the isolated impact of an error in the early life of the structure (virgin reliability); (ii) the impact of accumulated damages (multiple damages effect); and (iii) its impact associated with the degradation of the structure, or as part of the acceleration of the degradation process. However, it is also found that the whole evaluation is extremely dependent on the magnitude of the error in question.

Table 4. Robustness Index results

\begin{tabular}{ccccc}
\hline & $\boldsymbol{I}_{\boldsymbol{R}}^{\mathbf{1 0 0} \%}$ & $\begin{array}{c}\mathbf{R}_{\mathbf{k}} \\
\mathbf{1 0 0 \%}\end{array}$ & $\boldsymbol{I}_{\boldsymbol{R}}^{\mathbf{4 5} \%}$ & $\begin{array}{c}\mathbf{R}_{\mathbf{k}} \\
\mathbf{4 5 \%}\end{array}$ \\
\hline Damage 1 & $83.3 \%$ & 2 & $93.4 \%$ & 1 \\
Damage 2 & $88,9 \%$ & 3 & $96.9 \%$ & 2 \\
Damage 3 & $92.5 \%$ & 4 & $98.4 \%$ & 3 \\
Damage 4 & $99.4 \%$ & 5 & $99.0 \%$ & 5 \\
Damage 5 & $68,2 \%$ & 1 & $98.6 \%$ & 4 \\
Multiple & $47.1 \%$ & & $88.4 \%$ & \\
Damages & & & & \\
\hline
\end{tabular}

In cases where the accumulation of some errors does not bring the structure to its collapse, it is important to evaluate its impact on the serviceability over the life of the structure, since the premature failure of a service limit state due to errors in design and construction, is also one of the countless repercussions of human errors in the failure of structures.

Bearing in mind the target reliability index it is important to point out that this value is reached for 
error 2, 3 and 5 , more or less, at $50 \%$ of the damage's magnitude. For damage 1 and multiple damages, the target index is reached, around $20 \%$ of the damage's magnitude.

\section{References}

[1] J. Scheer, Failed Bridges - Case Studies, Causes and Consequences. Hannover: Ernst\&Sohn, 2010.

[2] A. Syrkov, "Review of bridge collapses worldwide 1966 - 2017," in IABSE Workshop Ignorance, uncertainty and human errors in structural engineering, 2017.

[3] I. Tylek, K. Kuchta, and A. RawskaSkotniczny, "Human Errors in the Design and Execution of Steel Structures-A Case Study," Struct. Eng. Int., vol. 27, no. 3, pp. 370-379, 2017.

[4] E. Brehm et al., "Failure Identification: Procedural Causes and Corresponding Responsibilities Failure Identi fi cation: Procedural Causes and Corresponding Responsibilities," vol. 8664, 2018.

[5] K. D. Goepel, "Implementing the Analytic Hierarchy Process as a Standard Method for Multi-Criteria Decision Making In Corporate Enterprises - A New AHP Excel Template with Multiple Inputs," Proc. Int. Symp. Anal. Hierarchy Process, pp. 1-10, 2013.

[6] N. Galvão, J. C. Matos, D. V. Oliveira, and J. Fernandes, "Human Errors and Corresponding Risks in Reinforced Concrete Bridges Human Error Risk-Based Analysis," IABSE Conf. 2018, pp. 323-329, 2018.

[7] TNO DIANA, "User' s Manual - Element Library," TNO DIANA bv, 2008.

[8] NP EN 1992-1-1, "Projecto de estruturas de betão Parte 1-1: Regras gerais e regras para edifícios," Inst. Port. da Qual., 2008.

[9] EN 1992-1-2, "Eurocódigo 2 - Projecto de estruturas de betão Parte 1-2: Regras gerais Verificação da resistência ao fogo," CEN Eur. Comm. Stand., 2010.

[10] EN 1991-2, "Eurocode 1: Actions on structures - Part 2: Traffic loads on birdges,"
CEN - Eur. Comm. Stand., no. October, pp. 1-11, 2003.

[11] JCSS - Joint Committee on Structural Safety, "Probabilistic Model Code - Part 1-Basis of Design," Struct. Saf., no. March, p. 65, 2001.

[12] S. K. Choi, R. A. Canfield, and R. V. Grandhi, Reliability-based structural design. 2007.

[13] D. Wisniewski, "Safety Formats for the Assessment of Concrete Bridges," Guimarães Univ. Minho, no. March, 2007.

[14] JCSS - Joint Committee on Structural Safety, "Probabilisitc model code part 3: Resistance Models - Static properties of reinforcing steel," Jcss Probabilistic Model Code, vol. PART 3: RE, pp. 2-4, 2001.

[15] JCSS - Joint Committee on Structural Safety, "Probabilisitc model code part 3: Resistance Models - Stactic properties of presstressing steel (prestressed concrete)," Concrete, pp. 1-7, 2005.

[16] J. Campos e Matos, "Uncertainty Evaluation of Reinforced Concrete and Composite Structures Behavior," 2013.

[17] JCSS - Joint Committee on Structural Safety, "PROBABILISTIC MODELCODE PART 3: RESISTANCE MODELS," 2001, pp. 255-257.

[18] NP EN 1990:, "Norma Portuguesa Eurocódigo 0 - Bases para o projeto de estruturas," Inst. Port. da Qual., vol. 1999, p. 88, 2009.

[19] prEN 1991-7, "Eurocode 1: Actions on Structures: Part 1-7: General actions Accidental Actions," 2003.

[20] E. S. Cavaco, "Robustness of corroded reinforced concrete structures," 2013. 